Erratum

\title{
Erratum to "Integrated Approach to Investigate the Effect of Leachate on Groundwater around the Ikot Ekpene Dumpsite in Akwa Ibom State, Southeastern Nigeria"
}

\author{
N. J. George, ${ }^{1}$ A. I. Ubom, ${ }^{2}$ and J. I. Ibanga ${ }^{1}$ \\ ${ }^{1}$ Department of Physics, Akwa Ibom State University, Ikot Akpaden 520115, Nigeria \\ ${ }^{2}$ Department of Physics, University of Calabar, Cross River State, Nigeria \\ Correspondence should be addressed to N. J. George; nyaknojimmyg@gmail.com \\ Received 18 May 2014; Accepted 31 August 2014; Published 19 October 2014
}

Copyright (C) 2014 N. J. George et al. This is an open access article distributed under the Creative Commons Attribution License, which permits unrestricted use, distribution, and reproduction in any medium, provided the original work is properly cited.

Reference [18] in the paper entitled "Integrated approach to investigate the effect of leachate on groundwater around the Ikot Ekpene dumpsite in Akwa Ibom State, Southeastern Nigeria" is split into the following two references.

Orellana E, Moony AM (1966) Master curve and tables for vertical electrical sounding over layered structures. Interciencia, Escuela, Spain.

Papadopoulou MP, Varouchakis EA, Karatzas GP (2010) Terrain discontinuity effects in the regional flow of a Complex Karstified Aquifer. Environ Model Assess 15(5): 319-328. 

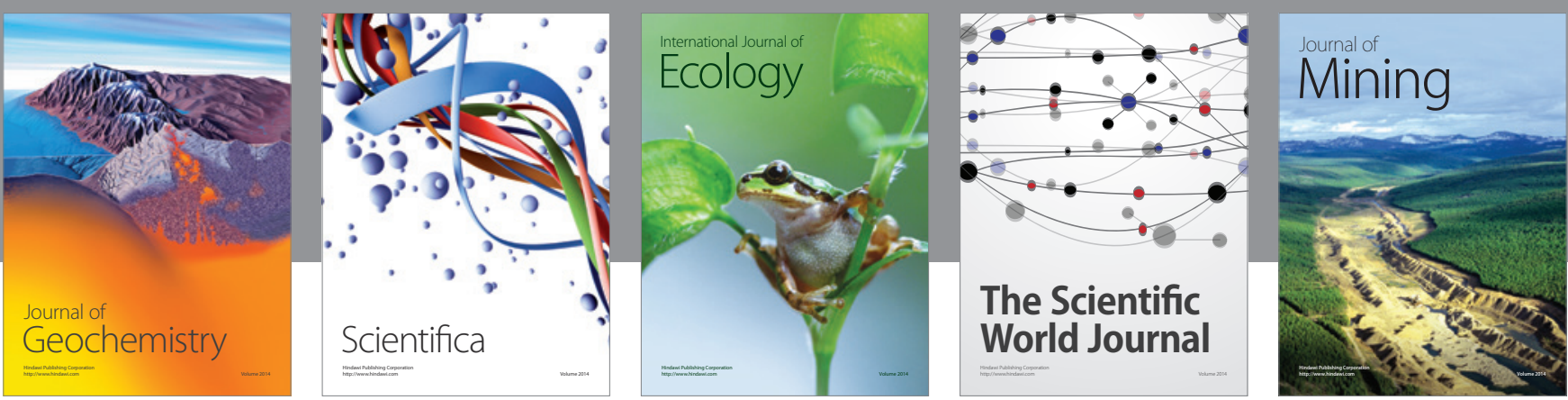

The Scientific World Journal
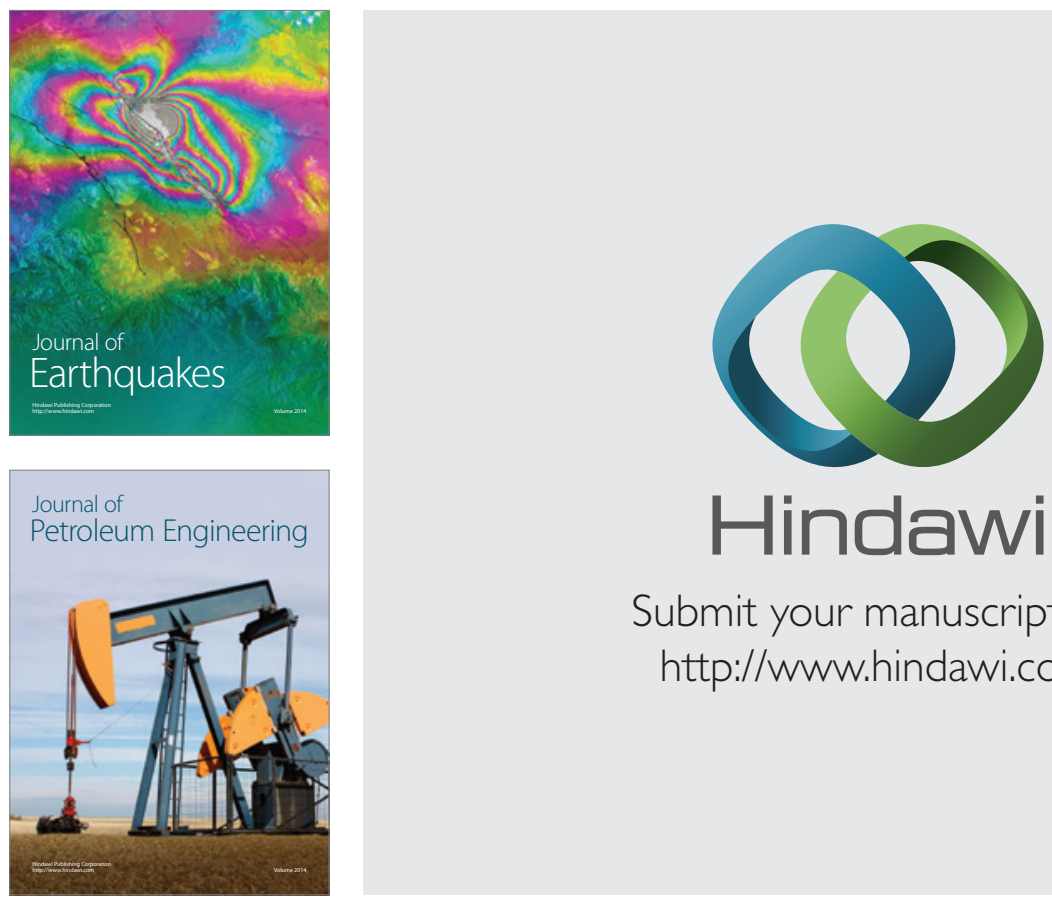

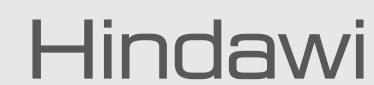

Submit your manuscripts at

http://www.hindawi.com
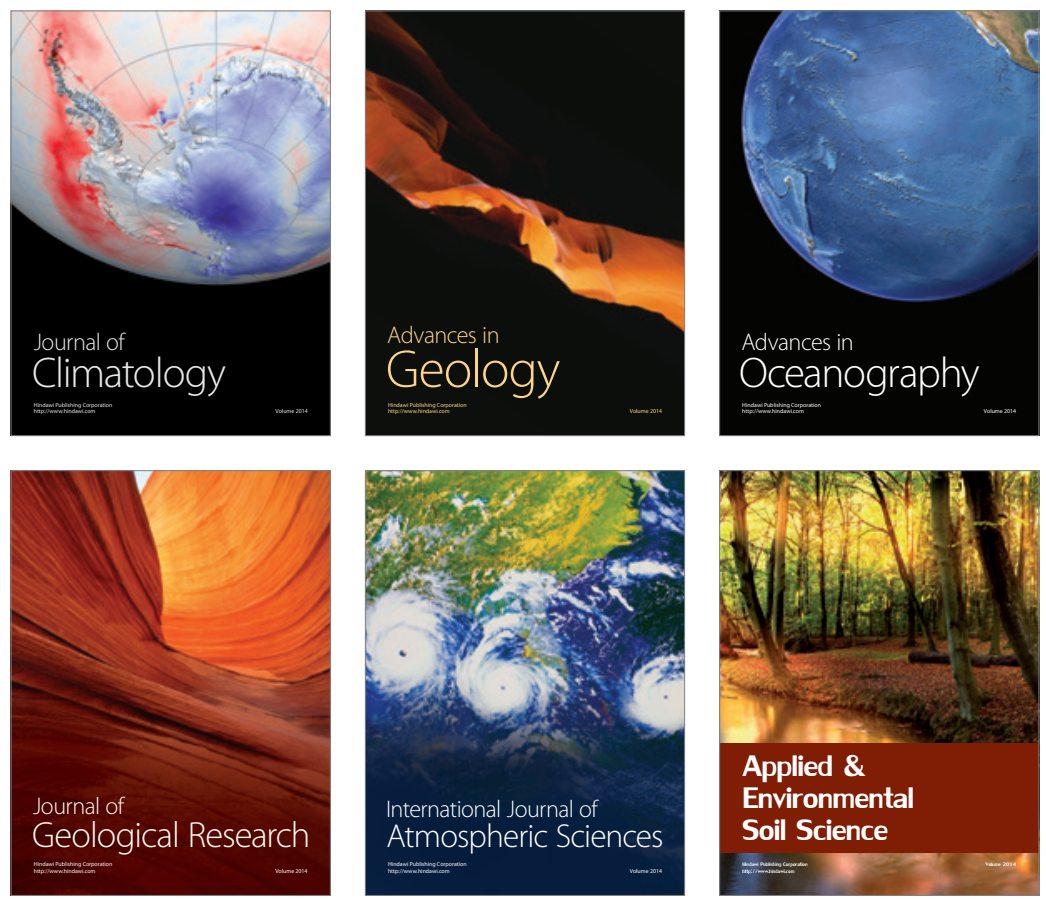
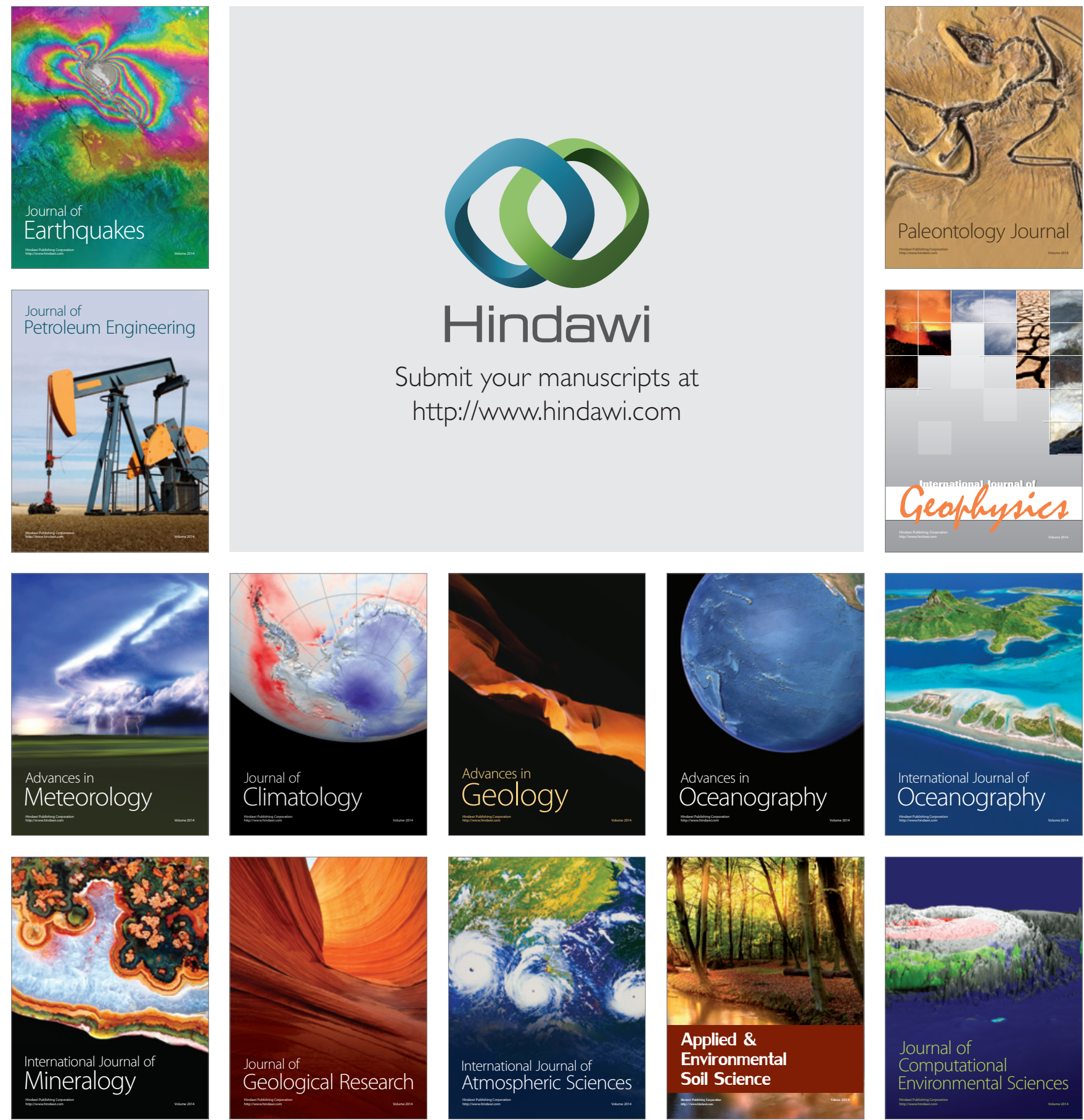